THE WELFARE COST OF PERMANENT INFLATION

AND OPTIMAL SHORT-RUN ECONOMIC POLICY

Martin Feldstein

NBER and Harvard University

Working Paper No. 201

NATIONAL BUREAU OF ECONOMIC RESEARCH, InC.

1737 Cambridge street

Cambridge, Massachusetts 02138

September 1977

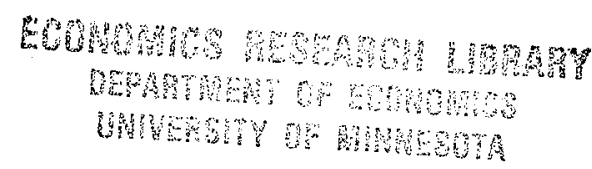

This paper has not undergone the review accorded official NBER publications; in particular, it has not been submitted for approval by the Board of Directors. 
THE WELFARE COST OF PERMANENT INFLATION AND OPTIMAL

SHORT-RUN ECONOMIC POLICY

Martin S. Feldstein ${ }^{*}$

It was not so long ago that most economists regarded the Phillips curve as a stable menu of policy options. A permanent reduction in unemployment appeared to be possible if the nation were willing to pay the price of a permanently higher rate of inflation. Even rather pessimistic estimates of the slope of the Phillips curve suggested that the price was well worth paying.

Today most economists reject this view in favor of Friedman's conclusion that the observed Phillips curve is only a short-run relationship and that the long-run equilibrium rate of unemployment is independent of the rate of inflation. This new understanding has radically transformed the perception of the policy problem. Since a permanent increase in the rate of inflation buys only a temporary reduction in unemployment, deciding whether to pursue an expansionary macroeconomic policy requires comparing the present value of the perpetual welfare loss caused by the increase in inflation with the welfare gain of the temporary reduction in unemployment. 1

*Harvard University and the National Bureau of Economic Research. I am grateful to the National Science Foundation for financial support of this research.

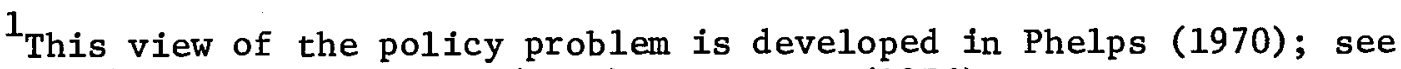
also Hall (1976), Modigliani (1977) and Tobin (1976). 
Most economists who have considered this dynamic optimization problem have concluded that the welfare loss of fully anticipated inflation is so small that there is a strong case for using expansionary macroeconomic policy to lower unemployment rates even if this results in a permanent increase in the rate of inflation. ${ }^{1}$ The present paper shows that the analysis leading to this conclusion involves a fundamental error.

The analysis developed here emphasizes that a vertical long-run Phillips curve may quite plausibly imply that the cost of reducing unemployment exceeds its benefit. When this is true, the analysis has the further implication that the benefit of increasing unemployment exceeds its cost (as long as the inflation rate is above its optimal level). In an important general case, it pays to deflate the economy in order to reduce inflation no matter how large the required temporary increase in unemployment. Even when this is not true, a very large increase in unemployment may be justifiably incurred to achieve a small permanent reduction in inflation.

$1_{\text {Hall (1976) presents an explicit calculation of the optimal path }}$ of unemployment and concludes that the unemployment rate should initially be depressed below its equilibrium value and then allowed to rise over a 10-year period to its steady state equilibrium; he calculates that the short-run output gains outweigh the permanent increase of two percentage points in the inflation rate. Tobin (1972, 1976) does not develop an explicit present value calculation but notes that the cost of an extra percentage point of inflation is "very small ... at most $1 / 1200$ of GNP" (1976, p. 6) and emphasizes the desirability of reducing unemployment even if inflation is increased. Solow (1975) and Modiglian1 (1977) also stress the small size of the welfare loss of anticipated inflation and the probable gain from an inflationary expansion policy. 


\section{Some Preliminaries}

Before turning to the central issue of this paper, it is necessary to discuss briefly some of the assumptions on which the analysis is based.

Posing the question of whether the gains from an expansionary macroeconomic policy outweigh the losses entails the assumption that policy can be at least temporarily effective in reducing unemployment. The present analysis thus implicitly rejects the original conclusion of the rational expectations approach that monetary and fiscal policy cannot influence the rate of unemployment (Lucas, 1972). Even within the strict rational expectations framework, we can accept the current short-run efficiency of monetary policy on the grounds that the public does not yet know the decision rule of the monetary authority and can therefore be fooled by a monetary expansion. Moreover, when long-term contracts or fixed investments constrain individual adjustment, monetary policy can continue to be effective in reducing unemployment by raising the rate of inflation. ${ }^{1}$ Without dealing more fully with these issues, the present paper will assume that expansionary policy can reduce unemployment temporarily but not permanently, i.e., that the Phillips curve is vertical in the long-run but not in the short-run.

In a perfectly competitive economy that was free of all distortions there would be no gain from reducing unemployment below its steady state

${ }^{1}$ See Fischer (1977), and Phelps and Taylor (1977) for a development of this view. 
equilibrium. The value of the extra output that would result would be outweighed by the value of the lost leisure, non-market production and investment in search activity. But with our actual system of taxation, unemployment insurance and other market distortions, the equilibrium rate of unemployment exceeds the optimal rate. ${ }^{1}$ I will therefore assume that a reduction in the unemployment rate from an initial value at or above its equilibrium represents a welfare gain.

It is important to distinguish the two quite different types of welfare loss that result from an increase in the rate of inflation. In the short-run, the change in the inflation rate is at least partly unanticipated while in the long-run the new higher level of inflation becomes fully anticipated. The extent of the short-run welfare loss depends on the speed with which the actual inflation rate adjusts to its new equilibrium value and the speed with which the public adjust their inflation expectations. ${ }^{2}$ Since the focus of the present analysis is on the long-run welfare cost of the permanently higher level of inflation, I will not examine the temporary cost of the change in inflation. ${ }^{3}$

${ }^{1}$ On these distorting effects, see Baily (1976), Feldstein (1973, 1976a) and Gordon (1973).

${ }^{2}$ See Flemming (1976) and Phelps (1972) for a discussion of the welfare costs associated with the adaptation to uncertain inflation and Frenkel (1976) for a discussion of the welfare cost of adaptation to an incorrectly perceived inflation rate.

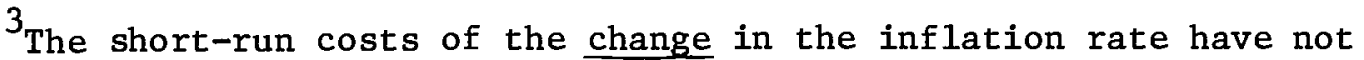
been explicitly recognized in the optimizing analyses cited above. Although an instantaneous adjustment of both the actual and anticipated inflation rates to the new equilibrium value could eliminate the welfare cost of the transition, this might also prevent any reduction in unemployment. 
In the long-run, any permanently maintained rate of inflation will become generally anticipated. Market participants will adjust their behavior but these changes cannot be sufficient to avoid all the adverse effects of inflation. A permanent welfare loss occurs because government policies do not adjust fully for inflation. The most commonly cited example of this is the reduced demand for money that results from inflation because interest is not paid on money balances. As Baily (1956) and Friedman (1969) emphasized, the supply of real money balances can be increased without social cost; it is therefore in principle optimal to eliminate the opportunity cost of holding money balances. This requires paying the same real interest rate on money balances as on other capital assets. Since nominal interest rates on currency are fixed at zero, this can only be achieved by deflating the price level at a rate equal to the real rate of return on capital (Friedman, 1969). The effect of inflation is to move the economy further away from this optimum. Inflation imposes an implicit tax on money balances, increasing the difference between the real yields on money and other assets and thus depressing even further the demand for money balances.

Phelps (1972) has emphasized that Friedman's conclusion is correct only in an economy in which non-distorting lump-sum taxes are available. When all taxes involve excess burdens, an optimal system of excise taxes is likely to require "taxing" money services as well. This implies that the opportunity cost of holding real money balances should exceed zero or, equivalently, that prices should not fall at a rate equal to the real rate of interest. Of course, it does not follow that the optimal rate 
of inflation is positive. In the analysis that follows, I will assume only that the actual rate of inflation exceeds the optimal rate. ${ }^{1}$

Although the nature of this welfare cost of inflation is widely recognized, its quantitative importance has been totally misperceived. To stress the potential importance of this single source of welfare cost, the present paper will focus exclusively on this distortion. The analysis that follows thus ignores the distortions of saving, portfolio choice and real investment that occur because tax liabilities are based on nominal capital income instead of real capital income. ${ }^{2}$ I also make the optimistic assumption that a constant rate of inflation can be sustained or at least that the variability of the inflation rate does not increase with its level. 3

$1_{\text {There is a further issue in an economy that taxes capital income. }}$ This may distort portfolio choice toward an excessive demand for money; some inflation would then offset this distortion. This is still consistent with the view that the optimal inflation rate is negative. Moreover, as Tobin (1958) and Mossin (1968) have shown, a tax on capital income may actually decrease the demand for money.

${ }^{2}$ See Feldstein (1976b) and Feldstein, Green and Sheshinski (1977) for an analysis of these distortions. Note that the mismeasurement of capital income for tax purposes is a problem even with a proportional income tax and is thus separate from the bracket rate distortion that occurs with a progressive tax. This source of welfare loss could be completely eliminated by rewriting the tax rules.

${ }^{3}$ If a higher rate of inflation is also a more varied rate, the increased uncertainty is an additional source of a permanent welfare cost. 


\section{The Welfare Loss of Permanent Inflation}

The first step in measuring the welfare cost of a permanent increase in the rate of inflation is to evaluate the loss that occurs at each instant of time. The traditional measure of this loss is the value of the liquidity services that society foregoes because of inflation, i.e., the area under the portion of the compensated demand curve that corresponds to the induced reduction in real money balances. This measure is correct only if there are no other distortions in the economy. It must be modified to make the analysis consistent with the view adopted in this paper that there are distorting taxes whose presence makes the optimal inflation rate greater than Friedman's "full liquidity" rate of deflation. Since this modification is only tangential to the basic point of the present paper, it is best to begin with the traditional measure. The more general framework will be developed in section 3 . Figure 1 illustrates the traditional static analysis. Curve DD represents the instantaneous demand for real money balances (m) as a function of the nominal interest rate ( $i)$. In the absence of capital income taxes or other distortions, the nominal interest rate equals the real marginal product of capital $(\rho)$ plus the rate of inflation $(\pi)$ : $i=\rho+\pi \cdot^{1}$ The full liquidity optimum of Friedman requires the inflation rate $\pi *=-\rho$ which implies $i_{0}=0$; this corresponds to the real

${ }^{1}$ In an economy with equity and debt finance, the real rate of interest on debt $(i-\pi)$ will be less than the marginal product of capital $(P)$; a more complete analysis that allows for this would not alter the conclusions. The taxation of interest income and deductabllity of interest expenses will complicate this analysis even if there is not equity finance; see Feldstein (1976b). 
$-7 a-$

Figure 1

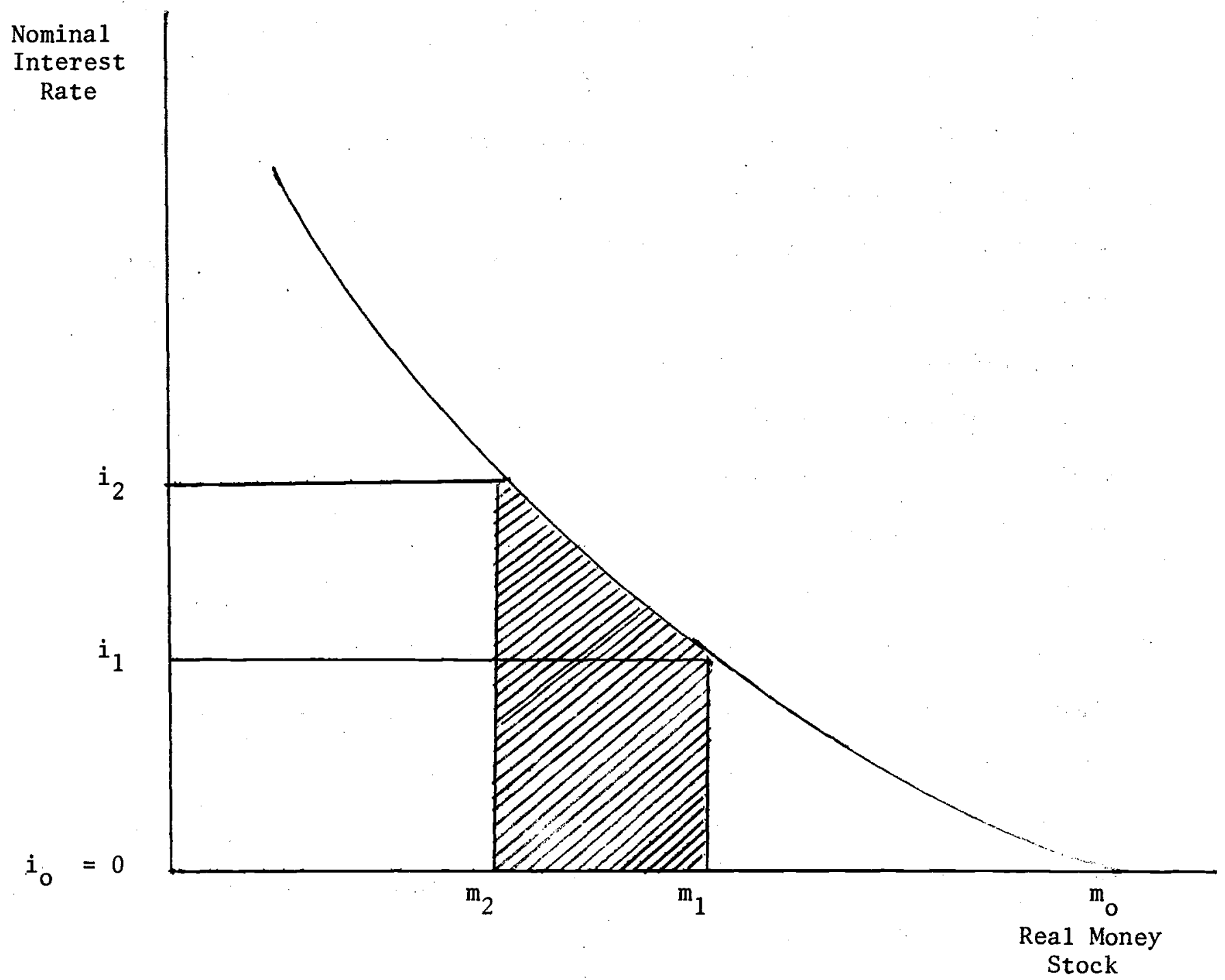


money balances of $m_{0}$. Any greater rate of inflation implies a positive rate of interest and therefore a welfare 1oss. An increase in the rate of inflation from $\pi_{1}$ to $\pi_{2}$ raises the interest rate from $i_{1}$ to $i_{2}$ and thus reduces the real money balances held by society from $m_{1}$ to $m_{2}$. When real balances are $\mathrm{m}_{2}$, the value of the services provided per unit time by an extra dollar of real balances is equal to the nominal rate of interest $i_{2}$. The value of the services lost when real balances are reduced from $m_{1}$ to $m_{2}$ is therefore the shaded area under the compensated demand curve.

The instantaneous welfare loss caused by any given increase in the rate of inflation thus depends on the induced change in the real money stock and on the prevailing rate of interest. Stated in an equivalent but more useful way, the instantaneous loss depends on the change in the inflation rate, the elasticity of the real money demand with respect to the rate of interest, and the size of the real money stock. The significance of this way of analyzing the loss is that the first two of the determinants can be expected to remain essentially constant when the economy is on an equilibrium growth path while the size of the real money stock grows with the economy.

The present value of a perpetual stream of such instantaneous losses depends on two things: (1) the rate at which the instantaneous losses grow in the future, and (2) the appropriate rate at which to discount future losses. The fundamental error in previous discussions of the deisrability of expansionary macroeconomic policy has been to ignore this growth of the real money stock in assessing the present 
value of the welfare loss that results from an increase in inflation. Recognizing the growth of the real money stock and therefore of the instantaneous welfare loss can change drastically the conclusions of a dynamic optimization.

When the growth of future losses is explicitly recognized, it is quite possible that the present value of the losses associated with a permanent increase in the rate of inflation is infinite; i.e., the present value grows without limit as a longer time horizon is taken into account. When the present value is infinite, the benefit of a temporary reduction in unemployment cannot be great enough to outweigh the cost. Similarly, the benefit of a permanent reduction in the rate of inflation would then outweigh the cost of any temporary increase in unemployment.

Let $\mathrm{L}_{0}$ be the instantaneous welfare loss when the equilibrium rate of inflation increases. Let this loss grow with time at rate $g$ and let the relevant discount rate be $r$. The present value of the permanent welfare loss is thus

$$
\delta=\int_{0}^{\infty} L_{0} e^{(g-r) s} d s .
$$

It is obvious that this integral converges to a finite value only if $r>g$; if not, the present value as of time zero of future losses continues to grow at rate $g-r$. To assess the practical importance of this possibility, it is necessary to consider the appropriate values of $g$ and $r$. The remainder of this section discusses the evaluation of $g$ for the simple case corresponding to Figure 1 . The value of $r$ is discussed in 
section 4. It is clear from equation 1 that, even when the present value is finite, it can be very large if $g$ is quite close to $r$. Section 3 derives the value of $L_{0}$ in the more general case in which there is a distorting income tax and shows that this extended framework does not alter the relevant value of $\mathrm{g}$.

Consider now the value of the instantaneous welfare loss at time $s$ that results when the rate of inflation increases from $\pi$ to $\pi+d \pi$. Letting $d i / d \pi=1$, the traditional welfare loss calculation implies ${ }^{1}$

$$
L_{s}=-\left(\frac{\partial m s}{\partial i}\right) \cdot i \cdot d \pi
$$

where $\partial m_{s} / \partial i$ is the slope of the compensated demand curve for real money balances. ${ }^{2}$ This can be rewritten as

$$
L_{s}=-\left(\frac{\partial m_{s}}{\partial i}\right) \frac{i}{m_{s}} \cdot m_{s} \cdot d \pi
$$

or

$$
\mathrm{L}_{\mathrm{s}}=\mathrm{m}_{\mathrm{s}} \mathrm{E}_{\mathrm{mi}} \mathrm{d} \pi
$$

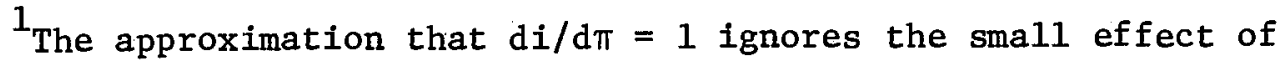
increased capital intensity on the marginal product of capital as well as the potentially larger effect of taxes on capital income. Since the net of tax interest rate is the relevant avariable, a capital income tax matters only if the borrowers' and lenders' tax rate differ; see Feldstein (1976b).

2 Note that this is the area of a trapezoid rather than a triangle because we start with an initial distortion wherever $\pi>-\rho$. When $\pi=$ - $\rho$, the relevant value of $i$ is $0.5 \mathrm{~d} \pi$ and 2.2 becomes the familiar triangle formula. 
If the elasticity of money demand is a constant, the instantaneous welfare loss that results from an inflation increase of $d \pi$ is always proportional to the real money stock. The rate of growth (g) of the instantaneous welfare loss is therefore equal to the rate of growth of the real money stock.

The standard assumption of all monetary growth analyses is that real money balances grow at the same rate as real income, i.e., at the sum of the rate of technical progress and the rate of growth of population. During the past 25 years in the United States, this rate of growth has averaged 3.3 percent per year. This has consisted of a population growth of 1.3 percent and a growth of per capital real GNP of 2.0 percent. A continuation of this in the future would imply $g=$ $0.033 .^{1}$

Note finally that the question of whether $g$ exceeds $r$ is quite different from the question of whether the economy is operating in the inefficient range where the per capita growth rate exceeds the marginal product of capital. Since $g$ is the growth rate of aggregate output, $g$ can exceed $r$ even though $r$ exceeds the per capita rate of growth. Moreover, as section 4 explains, $r$ is not the same as the marginal product of capital and can be very much less.

$1_{\text {The recent fall in the birth rate may signal the beginning of a }}$ lower rate of population growth for the indefinite future; if so, the appropriate value of $\mathrm{g}$ would also be lower. 


\section{Distortionary Taxes and the Welfare Loss of Inflation}

To measure correctly the instantaneous welfare loss caused by inflation requires taking into account the existence of other taxes that distort economic choice. There are two aspects of this modification. First, if the demand for money is not independent of all other taxed goods, the welfare loss caused by a change in the rate of inflation depends on the other tax rates and the cross elasticities of demand. Second, the higher rate of inflation raises revenue which permits a reduction in the other distorting tax rates. The current section derives the appropriate measure of the welfare loss for an economy with an income tax and shows that there is no change in the conditions required for the present value welfare loss to be infinite.

It is useful to begin with a completely general formulation. The economy can be described in terms of the quantity of real money, the quantities of $\mathrm{n}-2$ produced consumer goods, and the amount of leisure that the individuals consume. The instantaneous welfare loss is given by the famous Harberger-Hicks-Hotelling formula:

$$
L=-\frac{1}{2} \sum_{i=1}^{n} \sum_{j=1}^{n} S_{i j} T_{i} T_{j}
$$

where the $S_{i j}$ 's are the elements of the Slutsky matrix and the $T_{i}$ 's is the tax per unit of good $i$. The unit tax is the difference between the price paid by the consumer and the social cost of production.

If the first good is regarded as the liquidity service of real money balances, the corresponding tax is the rate of inflation plus 
the real marginal product of capital: $T_{1}=\pi+\rho$. The tax system is necessarily distorting because it is not possible to tax leisure, i.e., $T_{n}=0$. It is convenient to choose units for the other $n-2$ goods so that their costs of production are all equal to 1 . The tax per unit of good $i$ is therefore equal to the proportional ad valorem tax rate $t_{i}$. The loss in equation 3.1 can therefore be written as:

$$
L=-\frac{1}{2} S_{11}(\pi+\rho)^{2}-(\pi+\rho) \sum_{j=2}^{n-1} s_{i j} t_{j}-\frac{1}{2} \sum_{2}^{n-1} \sum_{2}^{n-1} s_{i j} t_{i} t_{j} \cdot
$$

The change in the instantaneous welfare loss can be regarded as the sum of the direct effect of the increase in $\pi$ and the indirect effect of the reductions in the tax rates that are made possible by the extra revenue raised by inflation. It will now be shown that this welfare change is proportional to national income and therefore that it will increase at the economy's growth rate, g. With as many different tax rates as commodities, there is no obvious way to specify how the extra revenue from inflation would be used to reduce commodity taxes. It is therefore useful at this point to introduce the simplifying assumption that the existing tax system is a proportional tax on all consumption (or, equivalently, on labor income) so that all of the $t_{i}$ 's are equal to a common value $t .^{1}$ It is clear from the form of the

${ }^{1}$ Another possibility would be to assume that the $t_{i}$ 's would be reduced to minimize $L$ with the given $\pi$. It is clear that the alternative assumption that I have adopted is not only simple to analyze but is probably a better approximation of reality. 
following analysis that the conclusion that the change in welfare is proportional to income could be obtained with any more general specification of commodity taxes and commodity tax reductions.

With all of the commodity tax rates equal, the effect of inflation on the instantaneous welfare loss can be written:

$$
\frac{d L}{d \pi}=\frac{\partial L}{\partial \pi}+\frac{\partial L}{\partial t} \frac{d t}{d \pi}
$$

where: $d t / d \pi$ is the change in the tax rate required to maintain constant total revenue when the revenue from inflation increases because of the higher rate of inflation; $\partial \mathrm{L} / \partial \pi$ is the partial effects on welfare of the inflation rate with the commodity tax rate constant; and $\partial \mathrm{L} / \partial \mathrm{t}$ is the corresponding partial effect on welfare of a change in t. To obtain these partial derivations, note that equation 3.2 with all the $t_{i}$ 's equal becomes:

$$
L=-\frac{1}{2} S_{11}(\pi+\rho)^{2}-t(\pi+\rho) \sum_{2}^{n-1} s_{i j}-\frac{1}{2} t^{2} \sum_{2}^{n-1} \sum_{2}^{n-1} s_{i j}
$$

This and 3.3 together imply

$$
\begin{aligned}
\frac{d L}{d \pi}= & -s_{11}(\pi+\rho)-t \sum_{2}^{n-1} s_{i j}-\left\{(\pi+) \sum_{2}^{n-1} s_{i j}\right. \\
& +t \sum_{2}^{n-1} \sum_{2}^{n-1} s_{i j}, \frac{d t}{d \pi}
\end{aligned}
$$

The second and third terms represent the generalization of the traditional result of section 2 . 
Note first that $d t / d \pi$ is independent of the scale of the economy and is thus a constant in the long-run. To see this explicitly, note that $\mathrm{tX}$ is the tax revenue per period (where $\mathrm{X}$ is total consumption) and $\stackrel{\circ}{M} / p$ is the revenue from money creation (where $\stackrel{\circ}{M}$ is the change in the nominal money stock). Since the inflation rate is the difference between the growth rate of the nominal money stock (M/M) and the growth rate of real income $(\mathrm{g})$, the revenue from money creation can be written

$$
\frac{\stackrel{\circ}{\mathrm{M}}}{\mathrm{p}}=\mathrm{m}(\pi+\mathrm{g}) \text {. }
$$

Thus total revenue is $t X+m(\pi+g)$. If $X$ and $m$ were constants, $d t / d \pi$ would equal $\mathrm{m} / \mathrm{x}$. Allowing for the effects of $\pi$ and $t$ on both $\mathrm{m}$ and $\mathrm{x}$ yields the more general expression:

$$
\frac{d t}{d \pi}=-\frac{\frac{M}{X}+\frac{M}{X}(\pi+g) \frac{\partial \ln m}{\partial \pi}+t \frac{\partial \ln X}{\partial \pi}}{1+t \frac{\partial \ln X}{\partial t}+\frac{m}{X} \frac{\partial \ln m}{\partial t}}
$$

For given values of $\pi, t$ and $g$, the value of $d t / d$ therefore tends to an equilibrium constant. 1

The effect of inflation on the welfare loss can be rewritten from equation 3.5 with the compensated cross-derivatives replaced by the corresponding cross-elasticities: ${ }^{2}$

$1_{\text {This is clearly true if all of the proportional derivatives in } 3.7}$ are constants; it is also true in the long run if these derivatives approach any limiting value including zero.

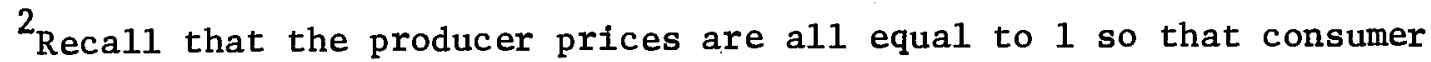
prices all equal $1+t$. Note that $x_{1}$ is the value of expenditure on good $i$ at the producer price. 
$(3.8)$

$$
\begin{aligned}
\frac{d L}{d \pi}= & -m\left\{E_{11}+\frac{t}{1+t} \sum_{j} E_{i j}+\left[\frac{\pi+\rho}{1+t} \sum_{j} E_{i j}\right.\right. \\
& \left.\left.+\frac{t}{1+t} \sum_{i} \sum_{j} E_{i j}\left(\frac{X_{i}}{M}\right)\right] \frac{d t}{d \pi}\right\} .
\end{aligned}
$$

Since inflation is by assumption above the optimal rate, $d L / d \pi$ is necessarily always positive. Because the entire expression is proportional to the real aggregate money supply, the incremental welfare loss will increase at the economy's rate of growth, $g$.

The present value of the welfare loss will therefore be finite only if $g$ is less than the relevant rate of discount $r$. We turn immediately to consider the relevant measure of $r .^{1}$

$1_{\text {Note that if }} \mathrm{g}<\mathrm{r}$ so that the loss is finite, the explicit optimization requires evaluating an expression like 3.8 subject to 3.7 and not just the simple expression (2.2) that is only correct if $t$ is zero. The analysis of Hall and others is inconsistent in assuming that the optimal inflation rate exceeds $-p$ while ignoring the effects of the other tax rates in evaluating the welfare effects of changes in $\pi$. 


\section{Discounting the Future Welfare Losses}

What rate of discount should be used to calculate the present value of the additional welfare loss that occurs in future year $\mathrm{T}$ because the inflation rate is permanently increased ${ }^{1}$ Since the additional welfare loss is evaluated as the increment to consumption that would be required to compensate individuals for the net adverse effect of the higher rate of inflation, choosing the discount rate is equivalent to measuring the marginal rate of substitution between future consumption and present consumption. It is therefore useful to distinguish two questions that are potentially quite different. First, how should we compare consumption by a single individual at two different times? Second, how should we compare consumption by members of successive generations?

The appropriate rate at which to discount additional consumption at different times by the same individual is the real net rate of interest faced by that individual. Since the incremental welfare losses that are to be discounted are assumed to be known with certainty, the appropriate discount rate should also be as close as possible to a riskless rate. It is difficult to select a market rate with which to measure this riskless rate of substitution without also being influenced by the degree of liquidity of the asset. The rate of return on time deposits or treasury bills would represent a riskless rate but would presumably understate the

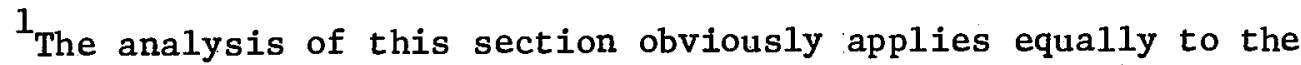
welfare gain from a reduction in inflation. 
intertemporal substitution rate because of the liquidity premium commanded by these assets. To be conservative and evaluate future welfare losses with a relatively high discount rate, I have selected the yield on longterm corporate bonds. For the past 25 years, the nominal rate of return on such bonds has averaged 5.3 percent. ${ }^{1}$ These interest rates were subject to personal taxation at marginal tax rates that varied between 14 percent and more than 90 percent. If we use a relatively low marginal tax rate of 20 percent, we will continue to overstate the relevant discount rate; this tax rate implies a net nominal rate of interest of 4.2 percent. During the same 25-year period, the consumer price index increased at an average rate of 3.2 percent. The real rate of return after tax was therefore only 1.0 percent. This method of evaluating $r$ clearly implies that $r$ is less than the real growth rate of nominal income of 3.3 percent. ${ }^{2}$

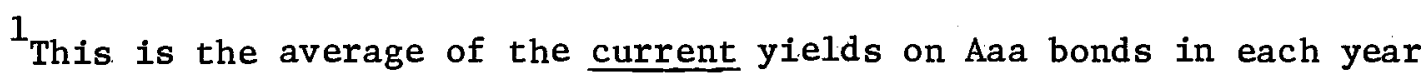
from 1952 to 1976. Since nominal yields rose, an investor over this period would have experienced a capital loss that lowered his nominal return. This is ignored in the current calculation as a further step to obtain a relatively conservative estimate of the relevant discount rate.

2 This low real net rate of return is not the result of the recent high rate of inflation. During the subperiod with the most stable prices (1960-64), the inflation rate averaged 1.2 percent and the real yield on corporate bonds after a 20 percent personal tax was only 2.3 percent. This represented more than an equilibrium yield since it reflected an anticipation that the inflation rate would again rise. Feldstein, Green and Sheshinski (1977) show that, with our current tax rules, a very low real net rate of interest is consistent with a substantially higher real marginal product of capital. 
It is not uncommon to use a rate of discount estimated in this way to aggregate the consumption of members of different generations as well as the consumption by a single individual in different years. ${ }^{1}$ Its justification presumably rests on the implicit proposition that the generations are linked to each other by a "dynastic altruism" which. causes the current generation to allocate consumption between itself and future generations and that the preferences of the current generation are the ethically appropriate basis for a social welfare evaluation. If this view is accepted, the riskless real net rate of interest is the relevant value of $r$. The evidence that $r=0.01$ while $g=0.033$ would therefore imply that the present value of the welfare loss caused by a permanent increase in the rate of inflation is infinite. No temporary reduction in unemployment, no matter how large or long-lasting, could justify a permanent increase in inflation.

There is of course a quite different way of aggregating incremental consumption in different generations that uses an explicit social welfare function instead of the assumption that the generations are linked by an ethically appropriate dynastic altruism. The usual procedure in optimal growth theory implicitly assumes that each generation lives for only a single year and that the social welfare function is additive. In this context, the marginal utility of consumption by successive generations declines because technical progress increases per capita

$1_{\text {See, for example, Harberger's discussion of cost-benefit analysis }}$ (1974) and of the welfare cost of capital income taxes (1964). Friedman (1969) uses this rate to evaluate the gain from achieving the optimum quantity of money. 
consumption while the marginal utility of consumption varies inversely with per capita consumption. More specifically, if per capita consumption grows at constant rate $\gamma$ and the elasticity of the marginal utility with respect to consumption is $\varepsilon$, the marginal utility of consumption delcines at rate $\varepsilon \gamma$. This implies that increments to consumption can be aggregated by discounting at the rate $\varepsilon \gamma$.

This approach can be extended to recognize that individuals within each generation live for more than one year. The consumption in different years by the same individual can be combined by using the real net rate of interest faced by the individual. Thus each individual's stream of changes in consumption is converted in this way into an equivalent change in consumption in the first year of his economic life. These "equivalent consumption changes" are then aggregated over generations by using the time preference ratederived from the social welfare function, i.e., by discounting at $\varepsilon \gamma$.

When the problem is viewed in this way, it should be clear that the welfare losses caused by a permanent increase in the rate of inflation will be finite only if $\varepsilon \gamma>\mathrm{g}$. The intragenerational discount rate will influence the magnitude of the present value for any finite horizon but not the convergence of the perpetuity of incremental welfare losses. ${ }^{1}$

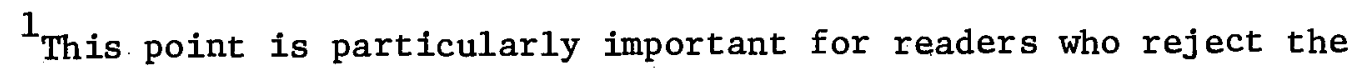
conclusion that the individual's rate of discount is less than $g$. Even if individuals use a very high discount rate, the intergenerational present value may be infinite. 
Since the growth of aggregate income $(\mathrm{g})$ is the sum of the per capita growth rate $(\gamma)$ and the rate of growth of population $(n)$, the convergence condition can be written $\varepsilon \gamma>\gamma+n$ or $\varepsilon-1>n / \gamma$. This condition cannot be checked empirically because $\varepsilon$ is inherently an unobservable parameter of the social welfare function. However, for $\mathrm{n} \geqq 0$, convergence obtains only if $\varepsilon>1$. The familiar logarithmic utility function implies $\varepsilon=1$ and therefore that the perpetuity of welfare losses does not converge to a finite value. More generally, with the values of $n=0.013$ and $\gamma=0.020$ that were observed during the past 25 years, convergence requires $\varepsilon>1.65$. Although this cannot be ruled out, it might well be regarded as implausibly high; it implies that in the past 25 years the marginal utility of a real dollar's worth of consumption has fallen by more than 55 percent. 1 If such a rapid decline is rejected, the elasticity of marginal utility is judged to be less than 1.65; with the observed growth rates, this implies an infinite present value for the welfare losses due to a permanent increase in inflation.

Although this line of reasoning does not establish that the welfare cost of increased inflation is infinite, it does show that such an infinite cost is quite plausible in a growing economy. More generally, it shows that even if the cost of additional inflation is finite, the

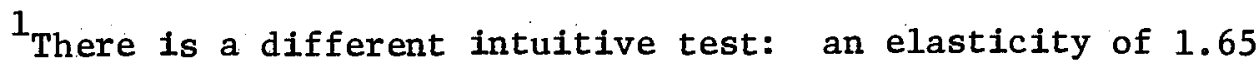
implies that a dollar's worth of consumption by a family with $\$ 10,000$ of income has the same utility value as 32 cents worth of consumption by a family with $\$ 20,000$. 
present value can be a very large multiple of the welfare loss during the first year. For example, if during the next 50 years $g=r=.03$ but then a drop in the birth rate makes $r-g=0.01$, the present value is 150 times the loss during the first year; the temporary reduction in employment might have to be quite substantial to justify such a loss. 1 Similarly, the analysis indicates that a deflationary policy may be justified if the inflation rate is above its optimum level. If the present value of the welfare effects of permanent changes in the inflation rate is infinite, it pays to reduce inflation no matter how large the required increase in inflation. More generally, even if the present value is finite, a very large deflation may be appropriate if it achieves even a small permanent reduction in inflation.

${ }^{1}$ If we use the simple expression of equation 2.4 to evaluate the first year loss, we find that an increase in the inflation rate of 0.01 causes a loss equal to its product with the real money supply and the elasticity of money demand with respect to the rate of interest. The relevant measure of the money supply includes inside as well as outside money. With $\mathrm{M}_{1}$ equal to approximately $\$ 300$ billion in 1977 and an elasticity of demand of one-third, the first year loss is approximately $\$ 1$ billion dollars. The present value of the growing perpetuity is thus $\$ 150$ billion on the basis of the assumption stated above. This is more than 8 percent of current GNP. 


\section{Should an Optima1 Policy be Postponed?}

Deflating the economy now in order to lower the rate of inflation imposes a cost on the present population while most of the benefits accrue in future years. It is natural therefore to ask whether it is ever optima1 to postpone a deflationary policy when deflation is warranted. Postponement implies that the cost of deflation will be greater when it occurs but also that the benefit in each year after the deflation will be greater as well. Can the growth rate, $g$, and the discount rate, $r$, ever imply that a postponed deflation is preferable to an immediate deflation? ${ }^{1}$ Similarly, in the opposite case in which the short-run benefits of expansion exceed the long-run costs, it is natural to ask whether it might ever be better to postpone such an expansionary policy.

The problem is analyzed most easily if we use discrete time and assume that the entire loss $\left(L_{0}\right)$ due to increased unemployment occurs in the first period. ${ }^{2}$ The gain from reduced inflation begins in the next period at level $\mathrm{G}$ and grows at rate $\mathrm{g}$. The effects of deflation are thus characterized by the sequence

$1_{\text {Note that the problem discussed here is not the optimal time path }}$ of a deflation but whether the entire deflation should be postponed. The optimal timing of deflation depends on the dynamic properties of the short-run Phillips curve; see Phelps (1972).

2 See the previous footnote. Note that the value of $\mathrm{L}_{0}$ may be regarded more generally as the excess of the unemployment loss over the concurrent gain due to reduced inflation. 
(5.1) $\quad-\mathrm{L}_{0} \quad \mathrm{G} \quad(1+\mathrm{g}) \mathrm{G} \quad(1+\mathrm{g})^{2} \mathrm{G} \quad \ldots$

The current loss and the future gains are combined by discounting at rate $\mathrm{r}$. Deflation is justified if either (1) $\mathrm{g}>\mathrm{r}$ or (2) $\mathrm{g}<\mathrm{r}$ and $\mathrm{L}_{0}<$ $G /(r-g)$. Postponing the deflation changes the sequence from 5.1 to

$$
0 \quad-L_{0}(1+g) \quad G(1+g) \quad(1+g)^{2} G
$$

With postponement there is no gain or loss in the first period. The loss occurs in the second period and is larger by a factor of $1+g$. The gain begins in the third period and is always larger by a factor of $1+\mathrm{g}$. The net effect of postponement is the difference between these two sequences or:

$$
\mathrm{L}_{0} \quad-\mathrm{L}_{0}(1+\mathrm{g})-\mathrm{G} \quad 0 \quad 0 \quad \ldots
$$

Only the first two periods are affected; there is no difference in subsequent periods. The present value of this two-period time stream is

$$
\begin{aligned}
V & =L_{0}-\frac{L_{0}(1+g)+G}{1+r} \\
& =\frac{1}{1+r}\left[(r-g) L_{0}-G\right] .
\end{aligned}
$$

Since deflation is optimal, we know that either (1) $\mathrm{r}<\mathrm{g}$ or (2) $\mathrm{r}>\mathrm{g}$ but $\mathrm{L}_{0}<\mathrm{G} /(\mathrm{r}-\mathrm{g})$. If $\mathrm{r}<\mathrm{g}$, the value of $\mathrm{V}$ in 5.4 is clearly negative and postponement has a negative present value. Similarly, $r>g$ and $\mathrm{L}_{0}<\mathrm{G} /$ $(\mathrm{r}-\mathrm{g})$ also imply $\mathrm{V}<0$. 
Thus whenever deflation is optimal it should not be postponed. A similar analysis shows that when expansion is optimal it should also begin immediately. 1

$1_{\text {These conclusions might be reached directly by the following }}$ reasoning: If it pays to defer deflation from year $t$ to $t+1$, it must pay (with constant $g$ and $r$ ) to postpone indefinitely. This contradicts the conclusion that it is optimal to deflate. Therefore it cannot pay to postpone. The more explicit analysis of this section shows that the validity of this conclusion is not affected by the convergence or nonconvergence of the present value integral. 


\section{The Welfare Gain from Optimal Liquidity}

In his analysis of the optimum quantity of money, Friedman (1969) presented estimates of the instantaneous potential welfare gain and of a corresponding present value. He concluded that if the relevant interest rate was 5 percent, the potential annual welfare gain for 1968 was between $\$ 2.3$ billion and $\$ 3.9$ billion. Friedman then treated this as a level perpetuity and, discounting at 5 percent, concluded that the gain would have a present value of between $\$ 46$ billion and $\$ 78$ billion, or roughly eight percent of 1968 national income.

This estimate of the present value is a substantial understatement because it fails to take into account the future growth of the economy. With a growth rate of $g=0.033$, the present value equals the initial gain divided by 0.050 minus 0.033 ; i.e., 59 times the initial value. This raises the estimated present value (as of 1968) to between \$136 billion and $\$ 230$ billion, or roughly 25 percent of 1968 national income. 1 This analysis of section 4 indicates that 5 percent may be much too high as an estimate of the real net rate of interest. A lower value would imply a somewhat smaller instantaneous gain from a change to the optimal money supply but a much larger present value. If the discount rate is less than the growth rate, the present value of such a change is unbounded. ${ }^{2}$

$1_{\text {Friedman's analysis should also be modified to reflect the existence }}$ of other distorting taxes as outlined in section 3. This will lower the potential gain but the correction is likely to be much smaller than the effect of allowing for growth.

2 Friedman (1969) and Johnson (1971) noted that once the regulation preventing interest on demand deposits and on the balances of the commercial banks themselves were eliminated, the only gain from optimal inflation would be in the quantity of currency. Johnson argued that this would be too small to be of serious concern. This is clearly false in the unbounded case if the costs of adopting an optimal inflation rate are regarded as temporary. 


\section{Conclusion}

At a minimum, the present paper should serve as a warning against too easy an acceptance of the view that the costs of sustained inflation are small relative to the costs of unemployment. If a temporary reduction in unemployment causes a permanent increase in inflation, the present value of the resulting future welfare costs may well exceed the temporary short-run gain. Previous analyses have underestimated the cost of a permanent increase in the inflation rate because they have ignored the growth of the economy and therefore the growth of the future instantaneous welfare costs. In the important case in which the growth of aggregate income exceeds the social discount rate, no reduction in unemployment can justify any permanent increase in the rate of inflation. Quite the contrary, if the inflation rate is above its optimal level, the economy should then be deflated to reduce the inflation rate regardless of the temporary consequences for unemployment. ${ }^{1}$

${ }^{1}$ In addition to the liquidity effects that have been the focus of this paper, inflation affects economic welfare by changing the rate of saving. This effect is complex and depends on the particular form of the tax system. With no taxes or an indexed tax system, inflation reduces the yield on saving to the extent that a fraction of wealth is held in the form of money balances. With our current system of taxes, inflation also increases the effective rate of tax on capital income (Feldstein, Green and Sheshinski, 1977) and is therefore likely to reduce the rate of saving even more. Since the taxation of capital income causes the marginal product of capital to exceed the rate at which future consumption is discounted, any decrease in saving causes an additional annual welfare loss. In evaluating an expansionary policy, the loss due to this reduction in future saving and the gain due to the extra saving out of the temporarily higher income should both be taken into account. 
It should be clear that a vertical long-run Phillips curve and an aggregate growth rate that exceeds the social discount rate ${ }^{1}$ make the whole question of rational expectations irrelevant for determining the optimal direction for policy. It is not necessary to regard the short-run Phillips curve to be vertical to conclude that expansionary policies are inappropriate and that deflation is optimal. 2

The empirical issue that is central to the present analysis is therefore the form of the long-run Phillips curve. Is it really true that any temporary reduction in unemployment requires a truly permanent increase in the rate of inflation? And can the rate of inflation be permanently reduced by a temporary increase in unemployment? Or is every economy occasionally subjected to large shocks that effectively eliminate previous expectations and restart the inflationary process? I regard these as unsettled empirical questions. The current paper shows the importance of these questions for the appropriate direction of short-run macroeconomic policy.

Throughout the paper, I have purposely avoided the issue of whether a steady positive rate of inflation could actually be sustained

$1_{\text {Recall that }}$ this is not equivalent to production in the inefficient range where capital intensity exceeds the golden rule values.

2 of course, policies to reduce unemployment by removing distortions and adverse incentives may be optimal even when the appropriate macroeconomic policy is deflation; see Feldstein (1973 and 1976a). There is a separate problem if the shape of the short-run Phillips curve changes over time. For example, if a one percent change in unemployment alters the inflation rate by more today that it would a decade from now, it may be best to deflate now and reinflate in the future; I have ignored such questions throughout this paper. 
The danger of attempting such a policy is that any attempt to increase the mean rate of inflation may increase its variability and may cause an explosive spiral of inflation. ${ }^{1}$ The annual welfare cost of such unstable and uncertain inflation would be substantially greater than the welfare cost of fully anticipated inflation. Thus even with a high discount rate or an arbitrarily shortened horizon, the welfare loss of increased inflation could outweigh the temporary gain of reduced unemployment. Here again, the appropriate macroeconomic policy depends on the answer to a currently unsettled empirical question.

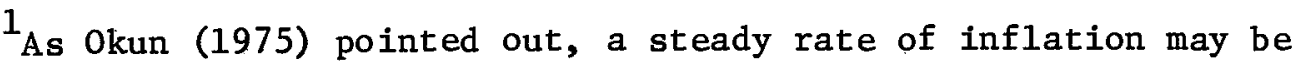
difficult to achieve because individuals regard any inflation as an indication of the government's inability to limit price increases and therefore encourages expectations of a further increase in the rate of inflation. 


\section{REFERENCES}

Bailey, M. J., "Welfare Cost of Inflationary Finance," Journal of Political Economy, Vol.64 (April 1956), pp.93-110.

Baily, Martin N., "Unemployment Insurance as Insurance for Workers," Econometrica, forthcoming, 1977.

Feldstein, Martin S., "Lowering the Permanent Rate of Unemployment," A Study prepared for the use of the Joint Economic Committee, Congress of the United States, August 1973. Washington: U.S. Government Printing Office, 1973.

, "Temporary Layoffs in the Theory of Unemployment," Journal of Political Economy, 1976a, Vol.84, No.5, pp.937-57. , "Inflation, Income Taxes, and the Rate of Interest:

A Theoretical Analysis," American Economic Review, Vol.66, No.3, December 1976b, pp.809-820. , Jerry Green, and Eytan Sheshinski, "Inflation and

Taxes in a Growing Economy with Debt and Equity Finance," Journal of Political Economy, forthcoming 1977.

Fischer, Stanley, "Long-Term Contracts, Rationa1 Expectations, and the Optimal Money Supply Rule," Journal of Political Economy, Vol.85, No.1, February 1977, pp.191-205.

Flemming, John S., Inflation. Oxford: Oxford University Press, 1976. Frenke1, Jacob A., "Some Dynamic Aspects of the Welfare Cost of Inflationary Finance" from R. I. McKinnon (Ed.), Money and Finance in Economic Growth and Development, Essays in Honor of Edward S. Shaw. New York: Marcel Dekker, Inc., 1976.

Friedman, Milton, "The Optimum Supply of Money" in The Optimum Supply of Money and other Essays (ed. M. Friedman). Chicago: Aldine Publishing Co., 1969. 
Gordon, Robert J., "The Welfare Cost of Higher Unemployment" in Brookings Papers on Economic Activity, Vol.1 (1976), pp.133-205.

Ha11, Robert E., "The Phillips Curve and Macroeconomic Policy," The Phillips Curve and Labor Markets, Vol.1 of the Carnegie-Rochester Conferences on Public Policy, a supplementary series to the Journa:l of Monetary Economics, Karl Brunner and Allan Meltzer (eds.), 1976, pp.127-148.

Harberger, Arnold C., "Taxation, Resource Allocation and Welfare," in J. Due (ed.), The Role of Direct and Indirect Taxes in the Federal Revenue System. Princeton: Princeton University Press, 1964. , Project Evaluation. Chicago: Markham Publishing Company, 1974 .

Johnson, Harry G., "Is There an Optimal Money Supply?" in M. Intriligator (ed.), Frontiers of Quantitative Economics. Amsterdam: NorthHolland Publishing Company, 1971.

Lucas, Robert E., Jr., "Expectations and the Neutrality of Money," Journal of Economic Theory, Vo1.4, No.2, Apri1 1972, pp.103-124. Modigliani, Franco, "The Monetarist Controversy or, Should we Forsake Stabilization Policies?" The American Economic Review, March 1977, pp. 1-19.

Mossin, Jan, "Taxation and Risk-taking: An Unexpected Utility Approach," Economics, 35 (February 1968), pp.74-82.

Okun, Arthur M., "Inflation: Its Mechanics and Welfare Costs," Brookings Papers on Economic Activity, 2:1975, pp.351-390.

Phelps, Edmund S., Inflation Policy and Unemployment Theory. New York: W. H. Norton \& Company, Inc., 1972. 
Phelps, Edmund S. and John B. Taylor, "Stabilizing Powers of Monetary

Policy under Rational Expectations," Journal of Political Economy, Vo1.85, No.1, February 1977, pp.163-190.

Solow, Robert M., "The Intelligent Citizen's Guide to Inflation," The Public Interest, No.38, Winter 1975, pp.30-66.

Tobin, James E., "Liquidity Preference as Behavior Towards Risk," Review of Economic Studies, 25 (February 1958), pp,65-86. , "Inflation and Unemployment," American Economic Review, Vo1.62, March 1972. , "Inflation Control as Social Priority," paper presented at Conference on the Political Economy of Inflation and Unemployment in Open Economics, Athens, Greece, October 21-23, 1976, unpub1ished. 